\title{
Lockdown to Contain the COVID-19 Pandemic: An Opportunity to Create a Less Polluted Environment in India
}

Special Issue:

Special Issue on COVID-19 Aerosol Drivers, Impacts and Mitigation (XI)

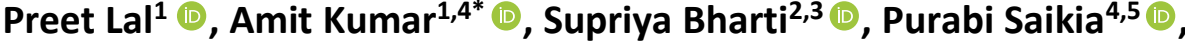 Dibyendu Adhikari6 $^{(0}$, M.L. Khan ${ }^{4,7^{*}}$ (1)}

\author{
${ }^{1}$ Department of Geoinformatics, Central University of Jharkhand, Ranchi-835205, Jharkhand, \\ India \\ ${ }^{2}$ Project Implementation Unit, National Highway Authority of India, Gurgaon, Haryana, India \\ ${ }^{3}$ Department of Civil Engineering, Dronacharya College of Engineering, Gurgaon, Haryana, India \\ ${ }^{4}$ Commission of Ecosystem Management, South Asia, IUCN, 110016 New Delhi, India \\ ${ }^{5}$ Department of Environmental Sciences, Central University of Jharkhand, Ranchi-835205, \\ Jharkhand, India \\ ${ }^{6}$ Plant Ecology and Environmental Technologies, CSIR-National Botanical Research Institute, \\ Lucknow, Uttar Pradesh, India \\ ${ }^{7}$ Department of Botany, Dr Harisingh Gour Vishwavidyalaya (A Central University), Sagar, \\ Madhya Pradesh-470003, India
}

\section{ABSTRACT}

Keeping aside the economic consequences, the imposition of strict lockdown in order to break the chain of deadly infection of SARS-CoV-2, has potentially improved the global environmental quality by facilitating a significant reduction in atmospheric pollution. In the present study, the level of atmospheric pollutants in India viz., $\mathrm{NO}_{2}, \mathrm{AOD}$, and $\mathrm{PM}_{2.5}$ before and during lockdown 2020 were assessed and compared using standard methods. The study revealed a significant reduction in $\mathrm{NO}_{2}$ i.e., > $10 \%$ change in $73.71 \%$ parts in India along with a high negative anomaly of AOD (<-1.0 in 32.92\% parts in India) primarily in the Indo-Gangetic Plains, western, southern, and eastern parts during the lockdown. The five megacities observed a sharp decline in the daily mean concentration of $\mathrm{PM}_{2.5}$ (ca. 32\% (Delhi) to 59.62\% (Bengaluru) during the lockdown 2020 as compared to the analogous period of lockdown in 2019. The study exhibited the very less contribution of seasonal and meteorological variables in the abatement of pollution during the lockdown period. The findings may be useful in guiding future strategies to maintain environmental quality by adopting a well-planned lockdown strategy.

Keywords: $\mathrm{NO}_{2}, \mathrm{AOD}, \mathrm{PM}_{2.5}$, Lockdown in India

\section{INTRODUCTION}

Coronavirus disease (COVID-19) caused by SARS-CoV-2 first reported in Wuhan, China in late December 2019 (Chen et al., 2020). Subsequently, it spreads to the larger parts of the globe very rapidly through human transmission (WHO, 2020a). Globally 2,973,264 cumulative cases of infection with $6.95 \%(206,569)$ of deaths, and $29.22 \%(868,806)$ of recovery has been reported till 26 April 2020 (WHO, 2020b). In India, the first positive case of COVID-19 was reported on 30 January 2020 in Kerala, when a student arrived from China (Reid, 2020), and later a set of cases was recorded across Delhi with a tourist group of 14 Italian, and 01 Indian on 03 March 2020 (Perappadan, 2020). A major outbreak of COVID-19 started in the month of March 2020 through its increasing number of cases across the country leading to 5000 infected cases with 27 death tolls till 07 April 2020 (Jha, 2020), and it reached a total of 28,074 infected cases with 826 deaths by 26 April 2020 (MoHF, 2020; WHO, 2020b). A similar trend was also observed in the case of 
COVID-19 recovery from 75 to 5913 patients during the period (07-26 April 2020). Considering human transmission as one of the significant causes of the pandemic, the Government of India (Gol) forced a complete countrywide lockdown targeting minimized social interactions, and mass gathering from 25 March 2020 in a phased manner to break the chain of the deadly infection. It is the biggest lockdown in history with a $\sim 1.3526$ billion population under the direct impact. The phase 1 of lockdown in India was started from 25 March to 14 April 2020, which later extended to 03 May 2020 in phase 2, and again continued to 17 May 2020 in phase 3. This lockdown led to the shutdown of all industries, businesses, parks, educational institutions, rail, road, and air transportations, and other crucial social interactions. Very essential activities and services including medical, security, and food supply remained out of shutdown implementation.

The complete lockdown throughout the country had brought major economic disruption in supply chains, tourism, and business travel (Boone et al., 2020; WTO, 2020). Though, the lockdown substantially affected the global economy, disrupt human lifestyle, mental health, as well as the livelihood of the marginal population at large, a positive impact on the environment has also been evident (Garg et al., 2020; Lal et al., 2020; Muhammad et al., 2020; Patel et al., 2020; Zalakeviciute et al., 2020) in the form of recovery, and rejuvenation of various natural processes. The discontinuation of various anthropogenic activities primarily industries and automobiles brought a significant reduction in the level of atmospheric pollution from local (Li and Tartarini 2020; Şahin 2020; Sfîcă et al., 2020; Wan et al., 2020) to global scales (Cadotte, 2020; Sharma et al., 2020; Spinelli and Pellino, 2020) as it linked with global warming, that exuberates climate change (Lahsen, 2008; Cushman, 2011; McLaughlin, 2011). Large scale planning forums like the Intergovernmental Panel on Climate Change (IPCC), International Union of Air Pollution Prevention and Environmental Protection Associations (IUAPPA), United Nation Environment Programme (UNEP), United Nation Framework Convention on Climate Change (UNFCCC) have continuously been working since long to deduce the solutions through ecosystem-based disaster risk reduction (EbDRR), and nature-based solutions (NBS) (Parry and Carter, 1998; de Nazelle et al., 2011; IPCC, 2018; Saikia et al., 2020).

Considering the environmental impacts of lockdown, an attempt has been made to quantify the spatio-temporal changes in the level of atmospheric pollution in India during the post lockdown period as compared to the previous. The objectives of the study were (i) to assess and compare the level of atmospheric pollutants (e.g., $\mathrm{NO}_{2}$ and $\mathrm{AOD}$ ) before and during the lockdown in the country including the concentration of $\mathrm{PM}_{2.5}$ in the five megacities of India, and (ii) to study the effectiveness of the lockdown in improving the environmental quality.

\section{DATA USED AND METHODOLOGY}

Satellite-based pollution data and pollution station data were used to monitor the variability in atmospheric pollutants for the pre lockdown (01-24 March 2020), and lockdown periods (25 March-20 April 2020). Tropospheric nitrogen dioxide $\left(\mathrm{NO}_{2}\right)$ column density datasets were acquired from the Sentinel 5-P TROPOMI sensor (Veefkind et al., 2012) were compared with the pre-lockdown to lockdown period in 2020 and analogous periods in 2019. Later, the percentage change of $\mathrm{NO}_{2}$ was estimated using Eq. (1).

Percentage Change of $\mathrm{NO}_{2}=\left(\left(\mathrm{NO}_{2} 2019_{L D}-\mathrm{NO}_{2} 2020_{L D}\right) / \mathrm{NO}_{2} 2019_{L D}\right) \times 100$

Daily aerosol optical depth (AOD) was acquired from MODIS Terra/Aqua MOD08, and MYD08 land datasets (Platnick et al., 2014, 2015) for the pre-lockdown period (01-4 March), lockdown period (25 March-20 April) in 2020, and analogous lockdown periods in 2019. Long-term observations (2000-2020) of the analogous periods of pre-lockdown, and lockdown were considered for anomaly estimation. Also, the standardized anomaly was calculated for the longterm variability of AOD (Eqs. (2) and (3)).

Normalized Anomaly = Observation - climatological mean

Standardized Anomaly = Normalized anomaly/Standard deviation 
Station data of $\mathrm{PM}_{2.5}$ of five megacities of India viz., Delhi (24 stations), Mumbai (10 stations), Kolkata (7 stations), Chennai (4 stations), and Bengaluru (7 stations) were acquired from Central Pollution Control Board (CPCB) (https://www.cpcb.nic.in/). The daily mean of all stations of each megacity was used to map the temporal variations of $\mathrm{PM}_{2.5}$ during the pre-lockdown and lockdown periods (25 March to 30 April) in 2020 and analogous lockdown periods in 2019. The TRMM based daily cumulative precipitation data were acquired from Giovanni (https://giovanni. gsfc.nasa.gov/giovanni/) and used to deduce its possible influence in the reduction of pollution levels in the select megacities.

\section{RESULTS AND DISCUSSION}

\subsection{Variability in Atmospheric Pollution}

A low to moderate reduction was observed in the concentration of tropospheric $\mathrm{NO}_{2}$ during lockdown $2020\left(0.00004-0.00006 \mathrm{~mol} \mathrm{~m}^{-2}\right)$ as compared to the pre-lockdown period ( 0.00006$0.00007 \mathrm{~mol} \mathrm{~m}^{-2}$ ) in the larger part ( 73.71\%) of India, primarily evident in the Indo-Gangetic Plains (IGP), and western parts (Figs. 1(a)-1(b)). When compared with the analogous lockdown period in 2019 (i.e., from 25 March to 20 April 2019), a moderate to a high reduction in $\mathrm{NO}_{2}$ ( 0.00001 to $\left.0.00004 \mathrm{~mol} \mathrm{~m}^{-2}\right)$ was observed during lockdown 2020 that clearly exhibited the impact of the total shutdown of human activities on the atmosphere (Figs. 1(b)-1(c)). Approximately $1 / 5^{\text {th }}(18.78 \%)$ part of India observed high to very high reduction (> 20\%) in $\mathrm{NO}_{2}$, which is primarily evident in the (a) eastern to south-western parts, as well as (b) in the northern to western parts of India (Fig. 1(d)). Although a large part of the country observed a sharp reduction in $\mathrm{NO}_{2}$ primarily in the regions of major sources due to sudden suspension of development activities (viz., mining activities, power generation, small to large sector industries, high vehicular movements, urban hubs, slash and burn agriculture), a few regions in eastern and north-eastern India observed a slight increase in $\mathrm{NO}_{2}$ may be attributed to an increase in mining, power generation, and associated activities during the lockdown period (Ranjan et al., 2020).

The lockdown 2020 due to the COVID-19 pandemic led to a decrease in the atmospheric pollutants and suspended particulate matters resulting in a decrease in AOD. The standardized anomalies (SAs) of AOD during the pre-lockdown period with respect to long-term observations (2000-2020) of analogous periods exhibited an overall high positive AOD anomaly (>1.0) in major parts of India (Fig. 2(a)). The SA of AOD during the lockdown 2020 showed a significant reduction

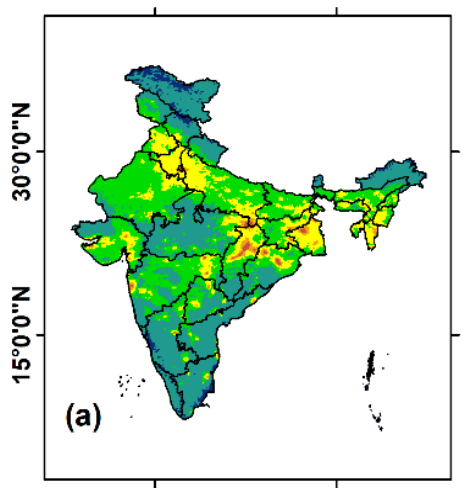

$75^{\circ} 0^{\prime} 0^{\prime \prime} \mathrm{E}$

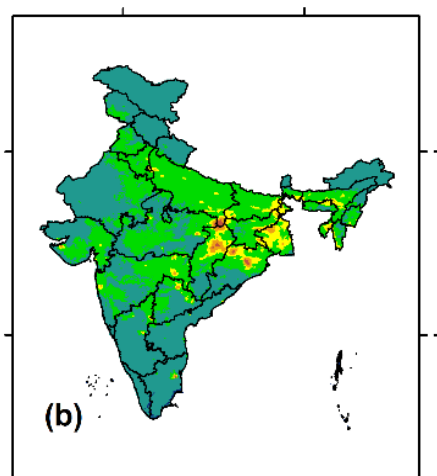

$75^{\circ} 0^{\prime} 0 " \mathrm{E} \quad 90^{\circ} 0^{\prime} 0^{\prime \prime E}$

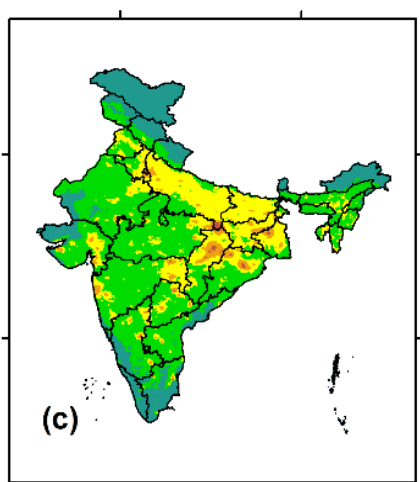

$75^{\circ} 0^{\prime} 0^{\prime \prime} \mathrm{E} \quad 90^{\circ} 0^{\prime} 0 " \mathrm{E}$

for (a), (b) and (c)

Tropospheric NO2 column number density $\left(\mathrm{mol} / \mathrm{m}^{\wedge} \mathbf{2}\right)$
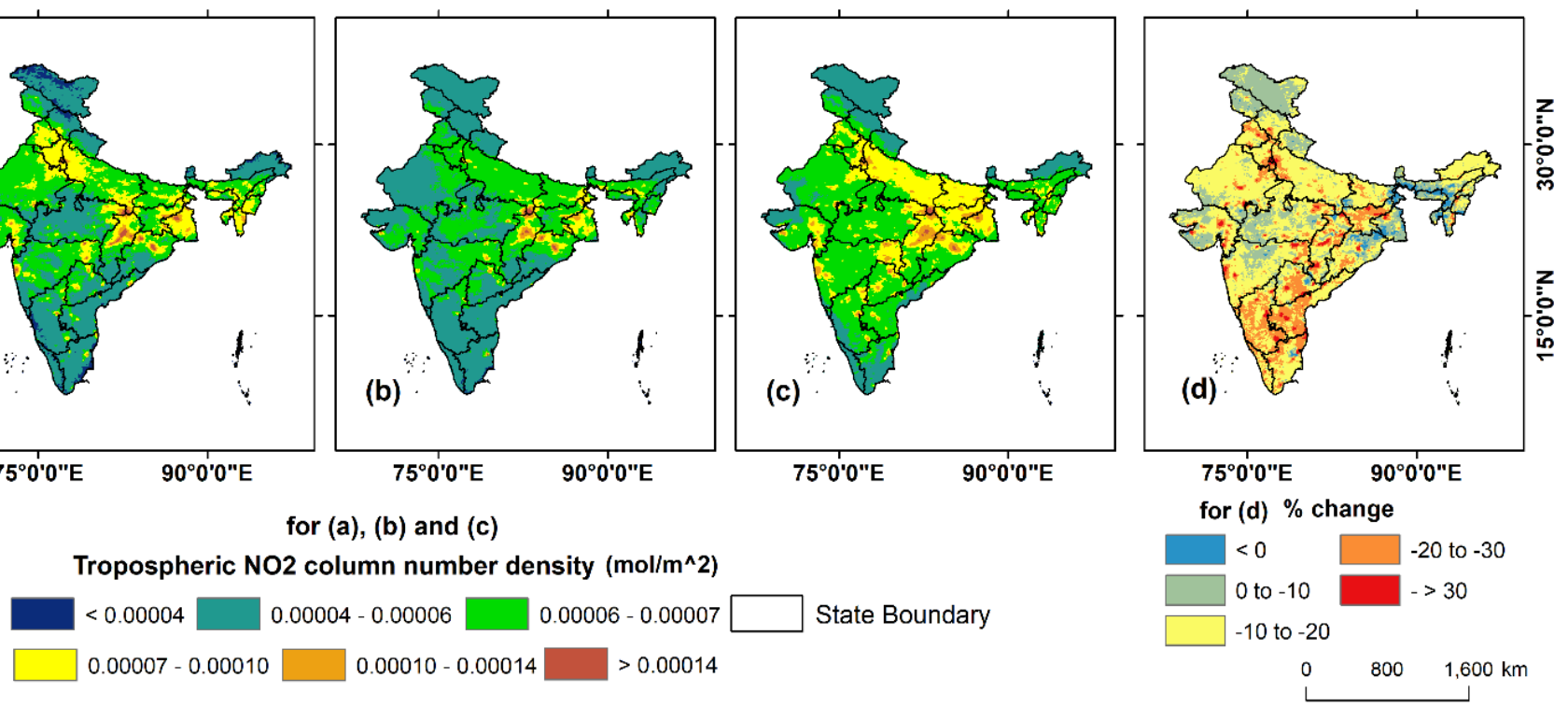

Fig. 1. Distribution of tropospheric $\mathrm{NO}_{2}$ during (a) pre-lockdown 2020, (b) lockdown 2020, (c) its comparison with analogous lockdown period in 2019, and (d) percentage change in $\mathrm{NO}_{2}$ concentration during lockdown 2020, and analogous lockdown period in 2019. 
(a)

(b)

(c)

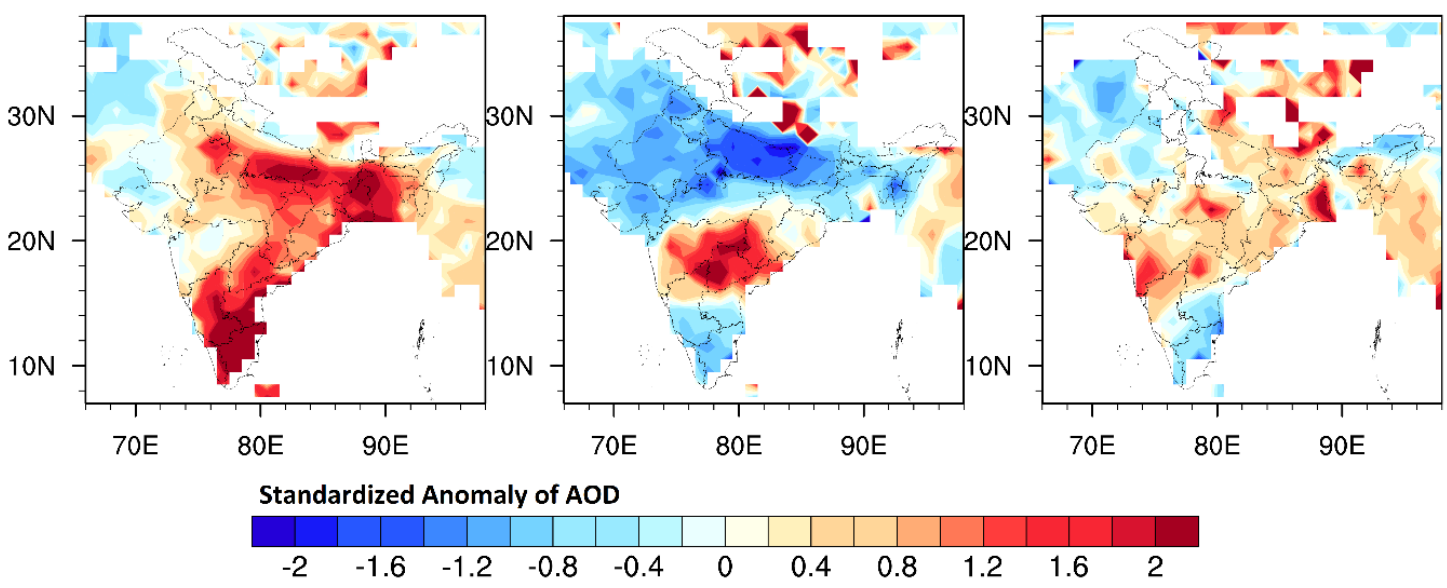

Fig. 2. Long-term observations (2000-2020) based standardized anomaly of AOD of (a) pre-lockdown 2020, (b) lockdown 2020, and (c) its difference with analogous lockdown period in 2019.

as apparent from the negative anomaly $(<-1.0)$ in the $32.92 \%$ parts of India. Considerable reduction in AOD was observed in the IGP ( - 0.4 to -1.2$)$ followed by western ( - 0.4 to -0.6$)$, southern ( - 0.2 ), and eastern ( -0.4) parts of India. However, $\sim 8.38 \%$ of the total geographical area comprising lower central India covering the states of Chhattisgarh, Maharashtra, and Odisha had a high positive AOD anomaly (> 1.0) during the lockdown 2020 (Fig. 2(b)). The analogous lockdown period in 2019 exhibited a large part of the country under positive low (0.4-0.8) to high (>1.0) anomaly of AOD, barring parts of extreme southern, western, and north-eastern India. While comparing the periodic observations of lockdown 2020 with analogous lockdown period in 2019 (Fig. 2(c)), a sharp reduction in AOD was evident illustrating its disassociation with seasonal variation.

An episodic variation in the concentration of $\mathrm{PM}_{2.5}$ was observed during the pre-lockdown period (2020) but remained high in most of the stations in Delhi (major range: $200-400 \mathrm{\mu g} \mathrm{m}^{-3}$; daily mean: $133 \mu \mathrm{g} \mathrm{m}^{-3}$ ) followed by Kolkata (50-300 $\mu \mathrm{g} \mathrm{m}^{-3}$; daily mean: $80 \mu \mathrm{g} \mathrm{m}^{-3}$ ), Mumbai (50-200 $\mathrm{g} \mathrm{m} \mathrm{m}^{-3}$; daily mean: $57 \mu \mathrm{g} \mathrm{m}^{-3}$ ), Bengaluru (50-150 $\mu \mathrm{g} \mathrm{m}^{-3}$; daily mean: $40 \mu \mathrm{g} \mathrm{m}^{-3}$ ), and Chennai (30-80 $\mathrm{g} \mathrm{m} \mathrm{m}^{-3}$; daily mean: $37 \mu \mathrm{g} \mathrm{m}^{-3}$ ) during working days, and low during weekends (Fig. 3). The study illustrated a sharp decline (ca. 46-75\% reduction) in the daily mean concentration of $\mathrm{PM}_{2.5}$ in all the five megacities during the lockdown 2020 (25 March to 20 April) as compared to the pre-lockdown period (01-24 March) in 2020. A significant reduction in $\mathrm{PM}_{2.5}$ was observed in Mumbai $(-75.44 \%$ change in daily mean), followed by Kolkata $(-64.62 \%)$, Delhi $(-58.87 \%)$, Chennai (-54.01\%), and the least reduction in Bengaluru (-46.88\%) during lockdown 2020 than pre-lockdown 2020 (Table 1). It is to note that the variations in the concentration of $\mathrm{PM}_{2.5}$ coincide with the phases of lockdown. A rise in the concentration of $\mathrm{PM}_{2.5}\left(100-200 \mu \mathrm{g} \mathrm{m}^{-3}\right)$ was observed after the end of the first phase of lockdown (14 April 2020) in Delhi, that may be attributed to the resumption of certain official activities with limited employees ( 33\%) led to the movement of automobiles. In contrast, Mumbai (50-70 $\left.\mathrm{g} \mathrm{m} \mathrm{m}^{-3}\right)$, and Kolkata $\left(20-50 \mu \mathrm{g} \mathrm{m}^{-3}\right)$ observed continuous decline during the subsequent phases (barring minor exceptions) exhibited the implication of a total shutdown of anthropogenic activities (Fig. 3).

The comparative analysis of the concentration of $\mathrm{PM}_{2.5}$ during the lockdown period of 2020 and its analogous periods in 2019 exhibited a reduction of ca. 32\% (Delhi) to $59.62 \%$ (Bengaluru) illustrating the implications of COVID-19 induced lockdown and its disassociation with seasonal variations. Looking into the possible influence of meteorological variables in a reduction of the concentration of $\mathrm{PM}_{2.5}$, the daily cumulative precipitation in the select megacities was analyzed. The study exhibited a very few episodic incidences of moderate precipitation (> $50 \mathrm{~mm} \mathrm{day}^{-1}$ ) during the lockdown period (2020) primarily in Chennai (02 incidences), and Bengaluru (01 incidence), in contrast, low precipitation (20-50 mm day ${ }^{-1}$ ) in Kolkata (02 incidences), and Bengaluru ( 01 incidence) that led to a slight reduction in the concentration of $\mathrm{PM}_{2.5}$. Barring these few exceptions, the major reduction in the concentration of $\mathrm{PM}_{2.5}$ is primarily attributed to the 

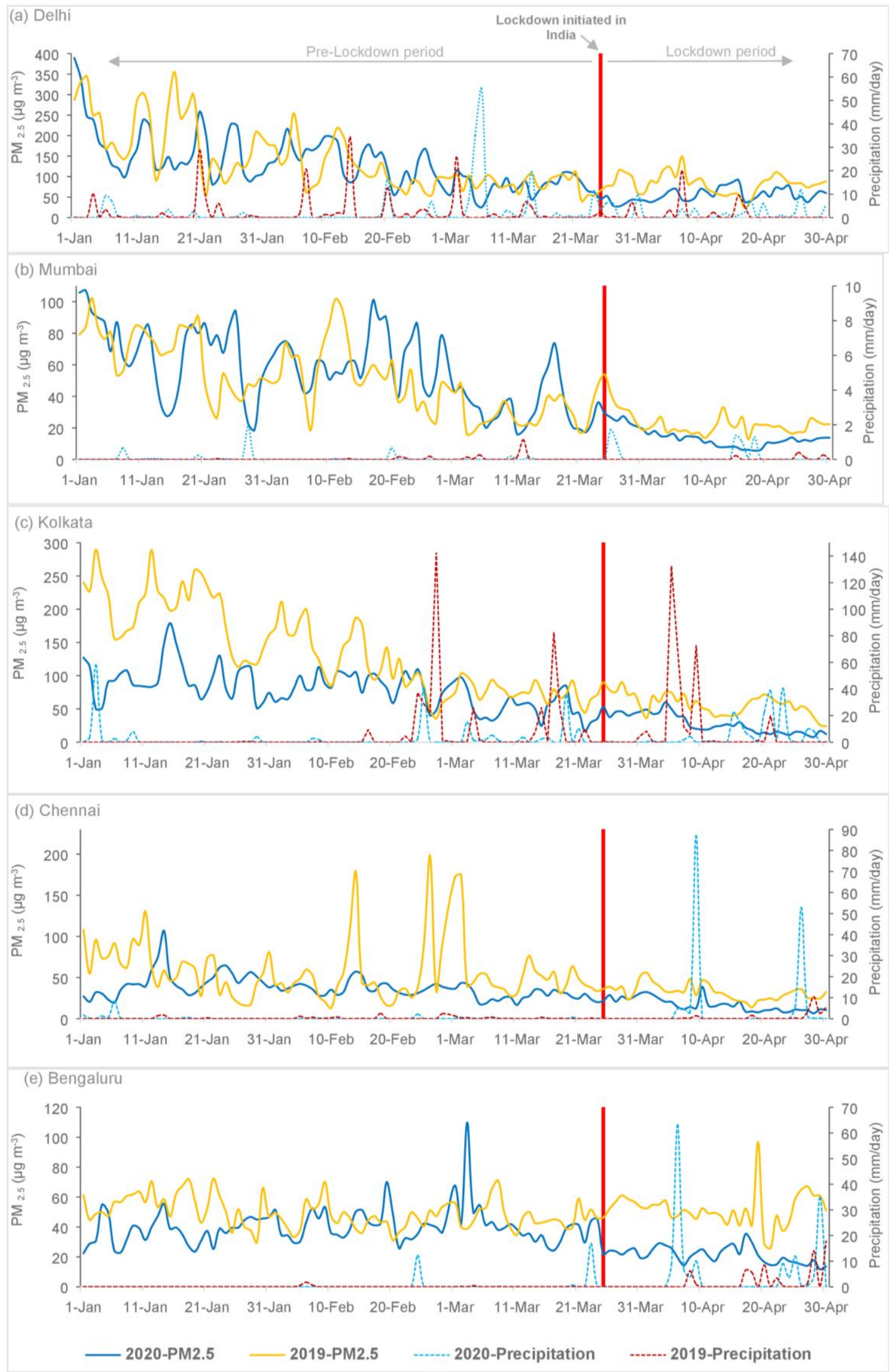

Fig. 3. Variability in the concentration of $\mathrm{PM}_{2.5}$ in (a) Delhi, (b) Mumbai, (c) Kolkata, (d) Chennai, and (e) Bengaluru during prelockdown 2020, during lockdown 2020, and analogous periods (pre-lockdown and lockdown) in 2019 (source: https://app.cpcbcc r.com/ccr/\#/caaqm-dashboard-all/caaqm-landing). 
Table 1. Daily mean concentration of $\mathrm{PM}_{2.5}$ in five megacities in India during pre and post lockdown 2020.

\begin{tabular}{llllll}
\hline Megacities & $\begin{array}{l}\text { Pre-lockdown 2020 } \\
\text { (01 January-24 } \\
\text { March 2020) }\end{array}$ & $\begin{array}{l}\text { Lockdown 2020 } \\
\text { (25 March-30 } \\
\text { April 2020) }\end{array}$ & $\begin{array}{l}\text { Analogous Period } \\
\text { of Lockdown } \\
\text { (25 March-30 } \\
\text { April 2019) }\end{array}$ & $\begin{array}{l}\text { \% Change during } \\
\text { pre-lockdown and } \\
\text { lockdown period } \\
\text { in 2020 }\end{array}$ & $\begin{array}{l}\text { \% Change during } \\
\text { lockdown 2020 } \\
\text { and analogous } \\
\text { lockdown in 2019 }\end{array}$ \\
\hline Delhi & 133 & 55 & 82 & -58.87 & -32.92 \\
Mumbai & 57 & 14 & 24 & -75.44 & -41.66 \\
Kolkata & 80 & 28 & 58 & -64.62 & -51.72 \\
Chennai & 37 & 17 & 32 & -54.01 & -46.87 \\
Bengaluru & 40 & 21 & 52 & -46.88 & -59.62 \\
Average & 69.4 & 27 & 49.6 & -59.964 & -46.558 \\
\hline
\end{tabular}

suspension of human activities during the lockdown period 2020. The least reduction in the $\mathrm{PM}_{2.5}$ in Bengaluru during the lockdown period was also attributed to the early state-wide lockdown (19 March 2020) than that of other megacities (25 March 2020).

The present study is a modest attempt to assess the impacts of national lockdown on the quality of the environment in terms of emission of $\mathrm{NO}_{2}, \mathrm{AOD}$, and $\mathrm{PM}_{2.5}$. We agree that the findings of this study are based on data for a relatively short time period, and the availability of more data on various emission parameters might potentially bring further clarity on the degree to which the lockdown has contributed to improving the environmental quality. Nonetheless, the results till now have shown a clear trend on the improvement in the quality of the environment. We strongly believe that the availability of emission data in the coming days would conform to and reinforce the findings of the present study.

\section{CONCLUSIONS}

The lockdown resulted in substantial improvement in the environmental quality with a sharp reduction in the concentration of various atmospheric pollutants. The daily mean $\mathrm{PM}_{2.5}$ decreased by ca. 46 to $75 \%$ in different megacities from the pre-lockdown period to $\sim 37$ days after the lockdown 2020. Although the atmospheric pollutants are influenced by meteorological variables, there were very limited incidences of moderate and low precipitation during the lockdown 2020. Also, the concentration of $\mathrm{PM}_{2.5}$ during the lockdown period of 2020 was reduced by $c a$. 32\% (Delhi) to $59.62 \%$ (Bengaluru) while comparing with the analogous periods in 2019, exhibiting the direct influence of COVID-19 induced lockdown in the abatement of atmospheric pollutants $\left(\mathrm{PM}_{2.5}\right)$ in the country. Similarly, there was a significant reduction in $\mathrm{NO}_{2}(>10 \%$ reduction in $\mathrm{NO}_{2}$ evident in $73.71 \%$ of India), and AOD (SA of $<-1.0$ in $32.92 \%$ of India) during the 27 days of lockdown 2020. The findings of this study may be useful for the government as well as different national and international organizations in developing effective management strategies for curbing environmental pollution in the future.

\section{ACRONYM}

AOD Aerosol Optical Depth.

CPCB Central Pollution Control Board.

EbDRR Ecosystem-based disaster risk reduction.

IPCC Intergovernmental Panel on Climate Change.

IUAPPA International Union of Air Pollution Prevention and Environmental Protection Associations.

LD Lockdown.

MoHFW Ministry of Health and Family Welfare, Government of India.

NA Normalized Anomaly.

NBS Nature-based solutions.

$\mathrm{NO}_{2} \quad$ Nitrogen Dioxide. 
$\mathrm{PM}_{2.5} \quad$ Particulate Matter less than 2.5 micrometer.

SA Standardized Anomaly.

UNEP United Nation Environment Programme.

UNFCCC United Nation Framework Convention on Climate Change.

WHO World Health Organization.

WTO World Trade Organization.

\section{ACKNOWLEDGMENTS}

The authors are very thankful to the Editor and anonymous reviewers for providing detailed comments that lead to a constructive improvement in the manuscript. Authors would also like to thank Giovanni, NASA for archiving Aerosol Optical Depth datasets. The authors wish to acknowledge the efforts of the Ministry of Family Health and Welfare (MoHFW), Govt. of India for concurrent updating of the COVID-19 cases in India on the online portal and Google Earth Engine for facilitating the access to the archive of publicly available satellite imagery and processing of Sentinel 5-P Tropomi datasets.

\section{REFERENCES}

Boone, L., Haugh, D., Pain, N., Salins, V. (2020). Tackling the fallout from COVID-19, in: Baldwin, R., di Maurop, B.W. (Eds.), Economics in the time of COVID-19, CEPR Press, p. 37.

Cadotte, M.W. (2020). Early evidence that COVID-19 government policies reduce urban air pollution (preprint). EarthArXiv. https://doi.org/10.31223/osf.io/nhgj3

Chen, N., Zhou, M., Dong, X., Qu, J., Gong, F., Han, Y., Qiu, Y., Wang, J., Liu, Y., Wei, Y., Xia, J., Yu, T., Zhang, X., Zhang, L. (2020). Epidemiological and clinical characteristics of 99 cases of 2019 novel coronavirus pneumonia in Wuhan, China: A descriptive study. Lancet 395, 507-513. https://doi.org/10.1016/S0140-6736(20)30211-7

Copernicus Climate Change Service (C3S) (2017). ERA5: Fifth generation of ECMWF atmospheric reanalyses of the global climate, Copernicus Climate Change Service Climate Data Store (CDS).

Cushman, G.T. (2011). Humboldtian science, creole meteorology, and the discovery of humancaused climate change in South America. Osiris 26, 19-44. https://doi.org/10.1086/661263

de Nazelle, A., Nieuwenhuijsen, M.J., Antó, J.M., Brauer, M., Briggs, D., Braun-Fahrlander, C., Cavill, N., Cooper, A.R., Desqueyroux, H., Fruin, S., Hoek, G., Panis, L.I., Janssen, N., Jerrett, M., Joffe, M., Andersen, Z.J., van Kempen, E., Kingham, S., Kubesch, N., ... Lebret, E. (2011). Improving health through policies that promote active travel: A review of evidence to support integrated health impact assessment. Environ. Int. 37, 766-777. https://doi.org/10.1016/j.env int.2011.02.003

Garg, V., Aggarwal, S.P., Chauhan, P. (2020). Changes in turbidity along Ganga River using Sentinel-2 satellite data during lockdown associated with COVID-19. Geomatics Nat. Hazards Risk 11, 1175-1195. https://doi.org/10.1080/19475705.2020.1782482

IPCC (2018). Summary for Policymakers of IPCC Special Report on Global Warming of $1.5^{\circ} \mathrm{C}$ approved by governments - IPCC.

Jha, D.N. (2020). Coronavirus cases in India cross 5,000; 1-year-old among 165 dead I India News - Times of India. Times India.

Kumar, P., Hama, S., Omidvarborna, H., Sharma, A., Sahani, J., Abhijith, K.V., Debele, S.E., ZavalaReyes, J.C., Barwise, Y., Tiwari, A. (2020). Temporary reduction in fine particulate matter due to 'anthropogenic emissions switch-off' during COVID-19 lockdown in Indian cities. Sustainable Cities Soc. 62, 102382. https://doi.org/10.1016/j.scs.2020.102382

Lahsen, M. (2008). Experiences of modernity in the greenhouse: A cultural analysis of a physicist "trio" supporting the backlash against global warming. Global Environ. Change 18, 204-219. https://doi.org/10.1016/j.gloenvcha.2007.10.001

Lal, P., Kumar, A., Kumar, S., Kumari, S., Saikia, P., Dayanandan, A., Adhikari, D., Khan, M.L. (2020). The dark cloud with a silver lining: Assessing the impact of the SARS COVID-19 pandemic on the global environment. Sci. Total Environ. 732, 139297. https://doi.org/10.1016/j.scitotenv.2 020.139297 
Li, J., Tartarini, F. (2020). Changes in air quality during the COVID-19 lockdown in Singapore and associations with human mobility trends. Aerosol Air Qual. Res. 20, 1748-1758. https://doi.org/10.4209/aaqr.2020.06.0303

McLaughlin, P. (2011). Climate change, adaptation, and vulnerability: Reconceptualizing societalenvironment interaction within a socially constructed adaptive landscape. Organ. Environ. 24, 269-291. https://doi.org/10.1177/1086026611419862

MoHFW (2020). COVID-19 India. https://www.mohfw.gov.in/index.php (accessed 27 April 2020).

Muhammad, S., Long, X., Salman, M. (2020). COVID-19 pandemic and environmental pollution: A blessing in disguise? Sci. Total Environ. 728, 138820. https://doi.org/10.1016/j.scitotenv.20 20.138820

Nicola, M., Alsafi, Z., Sohrabi, C., Kerwan, A., Al-Jabir, A., losifidis, C., Agha, M., Agha, R. (2020). The socio-economic implications of the coronavirus pandemic (COVID-19): A review. Int. J. Surg. 78, 185-193. https://doi.org/10.1016/j.ijsu.2020.04.018

Parry, M., Carter, T. (1998). Climate impact and adaptation assessment: A guide to the IPCC approach. Guide IPCC Approach. Earthscan, London.

Patel, P.P., Mondal, S., Ghosh, K.G. (2020). Some respite for India's dirtiest river? Examining the Yamuna's water quality at Delhi during the COVID-19 lockdown period. Sci. Total Environ. 744, 140851. https://doi.org/10.1016/j.scitotenv.2020.140851

Perappadan, B.S. (2020). COVID-19 | 6 members of Delhi patient's family test positive for coronavirus. The Hindu. https://www.thehindu.com/news/cities/Delhi/covid-19-6-membersof-delhi-patients-family-test-positive-for-coronavirus/article30980724.ece

Platnick, S., Hubanks, P., Meyer, K., King, M. (2014). MYD08_M3 MODIS/Aqua Aerosol Cloud Water Vapor Ozone Monthly L3 Global 1Deg CMG.

Platnick, S., Hubanks, P., Meyer, K., King, M. (2015). MOD08_M3 MODIS/Terra Aerosol Cloud Water Vapor Ozone Monthly L3 Global 1Deg CMG.

Ranjan, A.K., Patra, A.K., Gorai, A.K. (2020). Effect of lockdown due to SARS COVID-19 on aerosol optical depth (AOD) over urban and mining regions in India. Sci. Total Environ. 745, 141024. https://doi.org/10.1016/j.scitotenv.2020.141024

Reid, D. (2020). India confirms its first coronavirus case. CNBC.

Şahin, Ü.A. (2020). The effects of COVID-19 measures on air pollutant concentrations at urban and traffic sites in Istanbul. Aerosol Air Qual. Res. 20, 1874-1885. https://doi.org/10.4209/aaq r.2020.05.0239

Saikia, P., Kumar, A., Diksha, Lal, P., Nikita, Khan, M.L. (2020). Ecosystem-based adaptation to climate change and disaster risk reduction in Eastern Himalayan Forests of Arunachal Pradesh, Northeast India, in: Dhyani, S., Gupta, A.K., Karki, M. (Eds.), Nature-Based Solutions for Resilient Ecosystems and Societies, Disaster Resilience and Green Growth, Springer, Singapore, pp. 391408.

Sfîcă, L., Bulai, M., Amihăesei, V.A., Ion, C., Ștefan, M. (2020). Weather conditions (with focus on UV radiation) associated with COVID-19 outbreak and worldwide climate-based prediction for future prevention. Aerosol Air Qual. Res. 20, 1862-1873. https://doi.org/10.4209/aaqr.2020.0 5.0206

Sharma, S., Zhang, M., Anshika, Gao, J., Zhang, H., Kota, S.H. (2020). Effect of restricted emissions during COVID-19 on air quality in India. Sci. Total Environ. 728, 138878. https://doi.org/10.10 16/j.scitotenv.2020.138878

Shukla, K., Kumar, P., Mann, G.S., Khare, M. (020). Mapping spatial distribution of particulate matter using Kriging and Inverse Distance Weighting at supersites of megacity Delhi. Sustainable Cities Soc. 54, 101997. https://doi.org/10.1016/j.scs.2019.101997

Spinelli, A., Pellino, G. (2020). COVID-19 pandemic: Perspectives on an unfolding crisis. Br. J. Surg. 107, 785-787. https://doi.org/10.1002/bjs.11627

Veefkind, J.P., Aben, I., McMullan, K., Förster, H., de Vries, J., Otter, G., Claas, J., Eskes, H.J., de Haan, J.F., Kleipool, Q., van Weele, M., Hasekamp, O., Hoogeveen, R., Landgraf, J., Snel, R., Tol, P., Ingmann, P., Voors, R., Kruizinga, B., ... Levelt, P.F. (2012). TROPOMI on the ESA Sentinel-5 Precursor: A GMES mission for global observations of the atmospheric composition for climate, air quality and ozone layer applications. Remote Sens. Environ. 120, 70-83. https://doi.org/10. 1016/j.rse.2011.09.027

Wan, S., Cui, K., Wang, Y.F., Wu, J.L., Huang, W.S., Xu, K., Zhang, J. (2020). Impact of the COVID-19 
event on trip intensity and air quality in Southern China. Aerosol Air Qual. Res. 20, 1727-1747. https://doi.org/10.4209/aaqr.2020.07.0364

World Health Organization (WHO) (2020a). Report of the WHO-China joint mission on coronavirus disease 2019 (COVID-19). https://www.who.int/docs/default-source/coronavirus e/who-china-joint-mission-on-covid-19-final-report.pdf

World Health Organization (WHO) (2020b). India situation report. https://www.who.int/india/e mergencies/india-situation-report (accessed 27 April 2020).

World Trade Organization (WTO) (2020). Trade set to plunge as COVID-19 pandemic upends global economy. https://www.wto.org/english/news_e/pres20_e/pr855_e.htm (accessed 11 April 2020).

Zalakeviciute, R., Vasquez, R., Bayas, D., Buenano, A., Mejia, D., Zegarra, R., Diaz, V., Lamb, B. (2020). Drastic improvements in air quality in Ecuador during the COVID-19 outbreak. Aerosol Air Qual. Res. 20, 1783-1792. https://doi.org/10.4209/aaqr.2020.05.0254 